\title{
Minimization of Surface Roughness and Tool Vibration in CNC Milling Operation
}

\author{
Sukhdev S. Bhogal, Charanjeet Sindhu, Sukhdeep S. Dhami, and B. S. Pabla \\ National Institute of Technical Teachers and Training, Chandigarh 160019, India \\ Correspondence should be addressed to Sukhdev S. Bhogal; sukhdev_bhogal@yahoo.com
}

Received 15 September 2014; Revised 5 December 2014; Accepted 19 December 2014

Academic Editor: Eric S. Fraga

Copyright ( 2015 Sukhdev S. Bhogal et al. This is an open access article distributed under the Creative Commons Attribution License, which permits unrestricted use, distribution, and reproduction in any medium, provided the original work is properly cited.

Tool vibration and surface roughness are two important parameters which affect the quality of the component and tool life which indirectly affect the component cost. In this paper, the effect of cutting parameters on tool vibration, and surface roughness has been investigated during end milling of EN-31 tool steel. Response surface methodology (RSM) has been used to develop mathematical model for predicting surface finish, tool vibration and tool wear with different combinations of cutting parameters. The experimental results show that feed rate is the most dominating parameter affecting surface finish, whereas cutting speed is the major factor effecting tool vibration. The results of mathematical model are in agreement with experimental investigations done to validate the mathematical model.

\section{Introduction}

Due to its capability for enhancing product rate coupled with desired product quality, high-speed machining has gained popularity in manufacturing industry. However, higher values of cutting parameters used in high-speed machining adversely affect the surface roughness of workpiece and tool vibration. Tool vibration further lowers the component quality and reduces tool life. Empirical models can correlate surface finish, tool vibration, and tool wear to the machining parameters for machining of EN-31 die steel machining with tungsten carbide tool in high-speed machining.

Kline et al. [1] investigated the effects of vibration, deflection, and chatter of the tool workpiece system on roughness in end milling. Hamdan et al. [2] investigated the machining parameters like speed, feed, and axial depth of cut with dry and wet machining in high-speed machining of stainless steel using coated carbide tool for better surface finish. Suresh et al. [3] focused on machining mild steel by TiN-coated tungsten carbide cutting tool for developing a surface roughness prediction model by using response surface methodology (RSM). A genetic algorithm (GA) was used to optimize the objective function and the results were compared with RSM results. Kumar and Thirumurugan [4] introduced Taguchi's robust design method suitable to optimize the surface roughness in milling of die steel. The significant factors for the surface roughness in milling process were the spindle speed and the tool grade, with contribution of 30.347 and 29.933, respectively. Zhang and Chen [5] demonstrated a tool condition monitoring approach in an end milling operation based on the vibration signal collected through a low-cost, microcontroller-based data acquisition system. The examination tests of this developed system had been carried out on a $\mathrm{CNC}$ milling machine. Experimental studies and data analysis were performed to validate the proposed system. Routara et al. [6] investigated the parameters the influence of machining parameters on the quality of surface produced in $\mathrm{CNC}$ end milling. Experiments were conducted for three different workpiece materials to see the effect of workpiece material variation. It was found that the response surface models for different roughness parameters were specific to workpiece materials. Cui and Zhao [7] investigated the cutting performance of coated carbide tools in high-speed face milling of AISI H13 hardened steel. Chip morphology, tool life, tool wear mechanisms, and surface roughness were analyzed and compared for different cutting conditions. It was found that as 
the cutting speed increased, the chip morphology evolved in different ways under different milling conditions. Raju et al. [8] reported an integrated study of surface roughness and cutting parameters in end milling of 6061 aluminum alloy with HSS and carbide tools under dry and wet conditions. Genetic algorithm (GA) supported with the regression equation was utilized to determine the best combinations of cutting parameters providing roughness to the lower surface through optimization process. The value obtained from GA was compared with that of experimental value and was found to be reliable. Prajina [9] focused on RSM for the multiple response optimizations in CNC end milling operation to get maximum material removal rate, minimum surface roughness, and less force. In this work, quadratic equations were developed for cutting forces, surface roughness, and machining time considering the spindle speed, feed rate, depth of cut, and immersion angle as the cutting parameters using central composite design. Wang and Chang [10] investigated surface roughness in slot end milling of aluminum, while Öktem et al. [11] analyzed the optimum cutting condition leading to minimum roughness $\left(R_{a}\right)$ in end milling by combining RSM with neural network and genetic algorithm for $\mathrm{Al}$ and plastic mold parts. Rahim et al. [12] developed vibration measuring unit using a micro electromechanical system accelerometer, and experimental tests were carried out to characterize the device and the preliminary tests proved that the developed measurement unit was capable of sensing, measuring, and condition monitoring. Chen [13] studied the cutting force and surface finish during machining of medium hardened steel (45-55 HRC) using CBN tool and concluded that thrust force was the largest among the three cutting force components.

It is found from the literature that machining parameters like feed rate, cutting speed, and depth of cut influence both surface roughness and tool vibration. The research was mainly focused on determining the cutting force, tool wear, and surface roughness of the milling process. A few studies have been reported to minimize the tool vibration during machining. The main objective in this work is to find out the best combination of machining parameters in high-speed machining of tool steel using tungsten carbide tool to achieve low tool vibration and surface roughness. For this purpose mathematical models have been developed using the experimental data and developed models are tested for adequacy.

\section{Methodology}

In this work, response surface methodology (RSM) is used to develop mathematical models of tool vibration, surface finish, and tool wear. The main purpose of developing mathematical models with respect to machining responses and their factors is to optimize the machining process.

\subsection{Experimental Design. For an experiment $3 \mathrm{~K}$ full factorial} orthogonal array was used in order to get the output data uniformly distributed all over the ranges of the input parameters. The orthogonal array was chosen because of the fact that a minimum number of experimental trials were required which was more efficient in handling large number of factor
TABLE 1: Chemical composition of EN-31 tool steel.

\begin{tabular}{lc}
\hline $\mathrm{C}$ & $0.90-1.20$ \\
$\mathrm{Mn}$ & $0.30-0.75$ \\
$\mathrm{Si}$ & $0.10-0.35$ \\
$\mathrm{~S}$ & 0.040 \\
$\mathrm{P}$ & 0.40 \\
$\mathrm{Cr}$ & $1.00-1.60$ \\
\hline
\end{tabular}

TABLE 2: Technical details of milling cutter.

\begin{tabular}{lc}
\hline Item & Description \\
\hline Tool holder & BT40 \\
Tool diameter & $40 \mathrm{~mm}$ \\
Overhang length & $62 \mathrm{~mm}$ \\
Axial rake angle & $11^{\circ}$ \\
Insert designation & TPCN2204PDR \\
Insert clamping & Two \\
Number of inserts & Two \\
Insert thickness & $4.76 \mathrm{~mm}$ \\
Insert length & $22 \mathrm{~mm}$ \\
Insert type & Triangular \\
\hline
\end{tabular}

variables than any other traditional factorial design. Three input factors had been considered as cutting speed, axial feed, and depth of cut, respectively. The cutting conditions were selected by considering the recommendations in the handbook of cutting tool's manufacturer and the knowledge of practices, gathered through contemporary literatures on hard machining Korloy [14]. The three main selected parameters, cutting speed, axial feed, and depth of cut, were then coded to the levels from minimum to maximum.

2.2. Workpiece Material. EN-31 tool steel has good hothardness and toughness which covers a wide variety of industrial applications such as die casting, extrusion, hot die forging, and extrusion mandrels. It gives high temperature strength and good wear resistance. Plate of EN-31 steel of size $110 \mathrm{~mm} \times 100 \mathrm{~mm} \times 30 \mathrm{~mm}$ was used in this study. The workpiece material had hardness of $35 \mathrm{HRC}$. The nominal chemical composition and material properties of EN-31steel are given in Table 1.

2.3. Cutting Tool. The cutting tool used in the milling operation has a milling cutter of $40 \mathrm{~mm}$ diameter. The technical details of the milling cutter used in CNC milling are given in Table 2. Figure 1 shows the assembly of tool holder along with tool cutter used in CNC milling operation. In this experiment, two-bit cutter has been used. All the experiments have been performed on CNC milling machine of VM-10 of HURCO made.

2.3.1. Surface Roughness Measurement. Surface roughness is an important measure of product quality since it greatly influences the performance of mechanical parts as well as production cost. After milling experiments, the measurement 


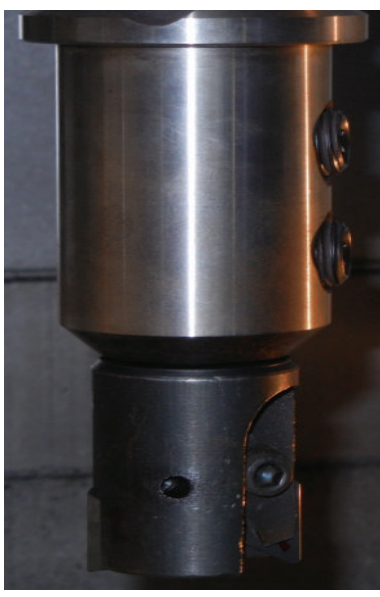

(a)

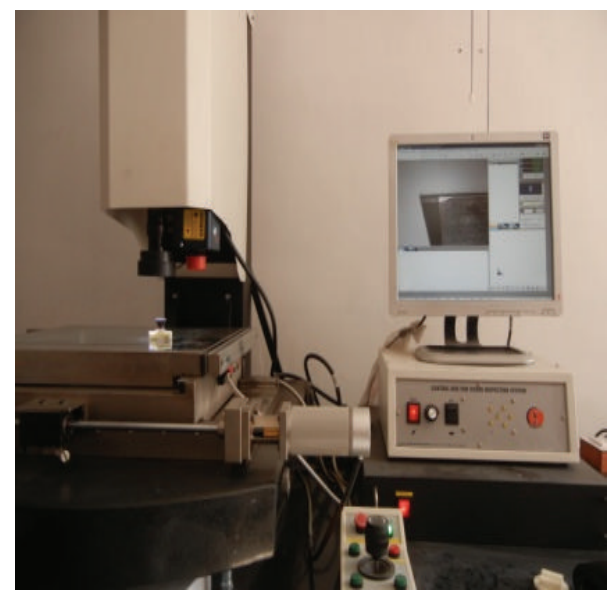

(b)

Figure 1: Milling cutter. (a) Tool holder and (b) machine vision system for measurement of flank wear of cutting tool bit.
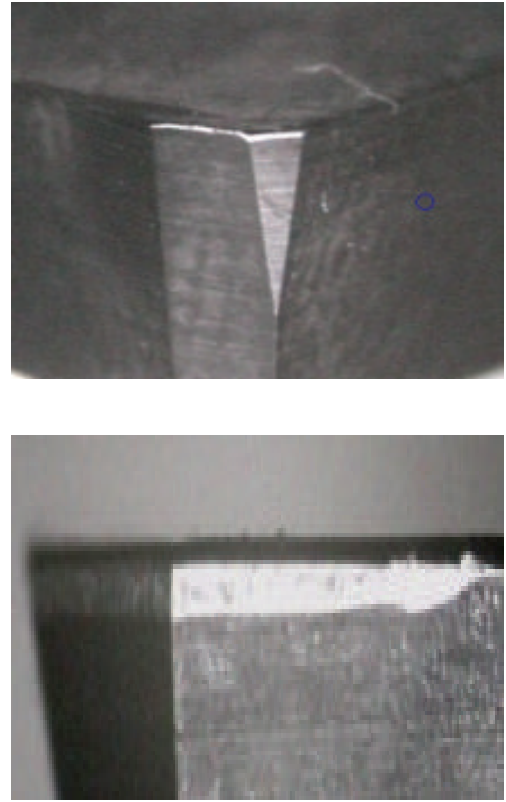

(a)
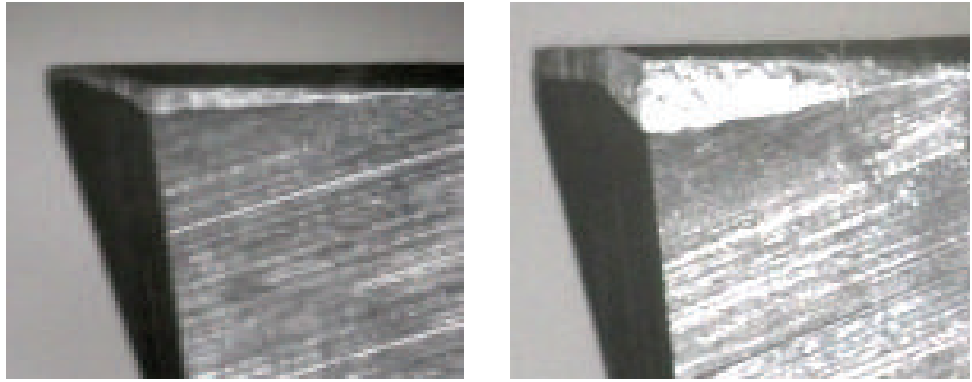

(i)

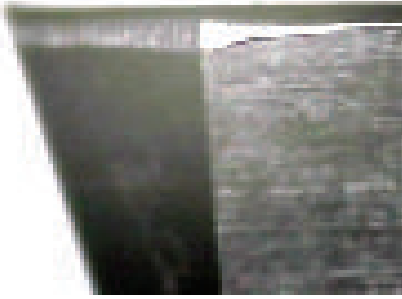

(b)

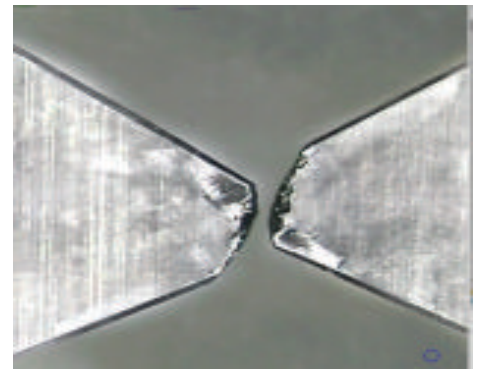

(ii)

FIGURE 2: (a), (b), and (c)(i) show images of different cutting inserts after milling showing flank and crater wear on machine vision system. (c)(ii) shows images of two different cutting inserts showing crater wear on machine vision system.

of arithmetical mean roughness $\left(R_{a}\right)$ was measured by surface roughness tester SJ 301 of Mitutoyo. The average value of three measurements of surface roughness was used as response value. The sampling length of the tester was adjusted to $4 \mathrm{~mm}$ (max).

2.3.2. Tool Wear Measurement. Flank wear of cutting tool has been measured for each combination of cutting conditions in accordance with the ISO standard for tool life testing at each end milling operation. It was measured on machine vision system as shown in Figures 1(b) and 2. Tool wear is calculated in terms of cutting time. Time taken by machine to cut the material until the flank wear attains the valve of 300 microns was measured by using the following formula:

$$
T=(\text { Number of passes }) \times(\text { time of one pass }) .
$$

2.3.3. Cutting Tool Vibration Measurements. The experiments were conducted on CNC milling centre. The machining was done with two-bit high-speed cutter under dry condition. A three axis accelerometer was attached to the spindle of machine in order to find out the acceleration vibration amplitude of cutting tool in $x$-, $y$-, and $z$-axes as shown in 


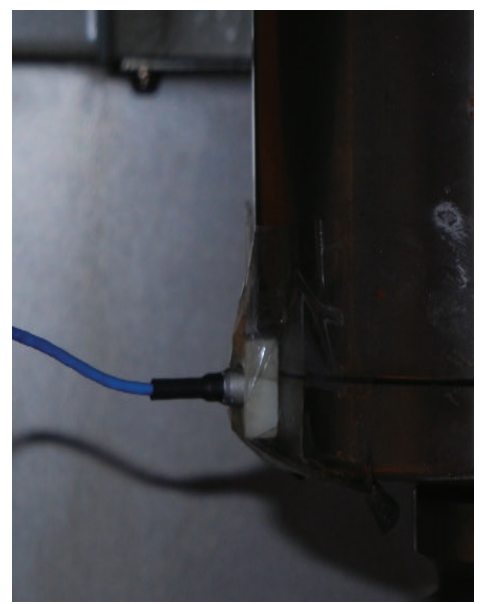

(a)
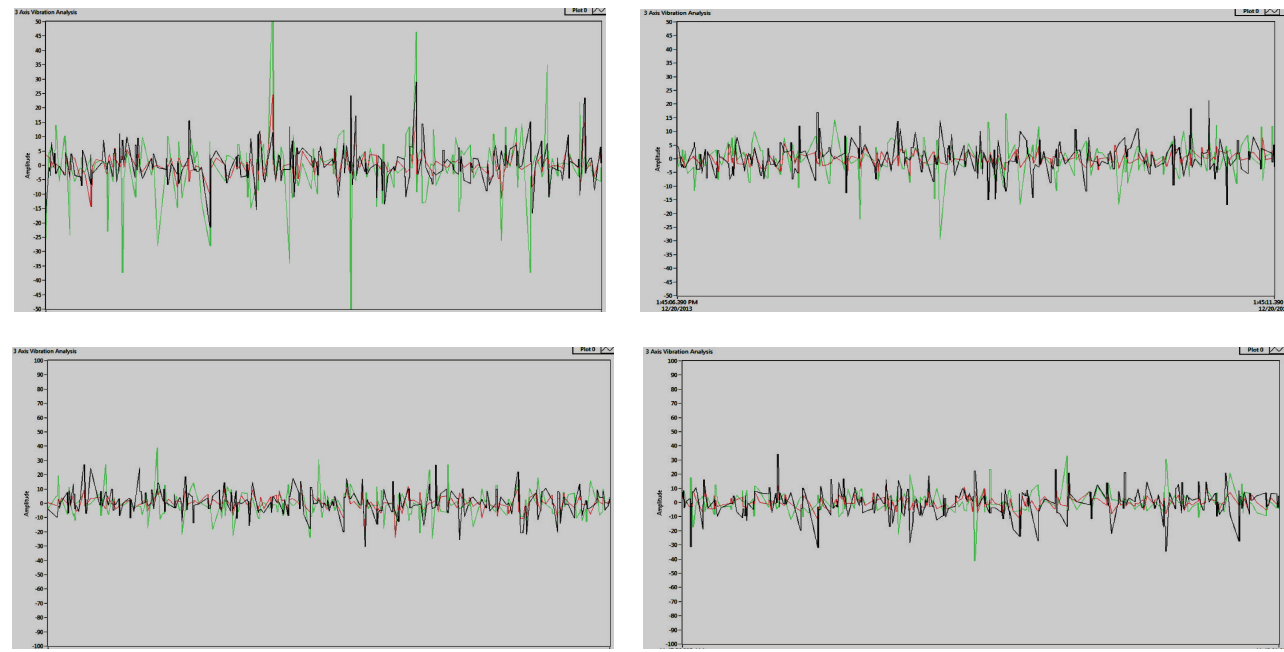

(b)

Figure 3: (a) Actual photograph of accelerometer attached to spindle of CNC milling machine. (b) Accelerometer vibration amplitude signal captured during machining at different machining parameters.

Figures 3(a) and 3(b). Vibration amplitude was measured by connecting an accelerometer to the machine spindle. The acceleration vibration amplitude is measured in the feed direction of the tool. The data acquired are tabulated to obtain the mathematical model.

\section{Development of Mathematical Model}

In this work, mathematical models have been developed using experimental results with the help of response surface methodology. The purpose of developing mathematical models relating the machining responses and their factors is to facilitate the optimization of the machining process.

3.1. Generation of Model. Response surface methodology (RSM) is a combination of mathematical and statistical techniques useful for modeling and analyzing the problems in which several independent variables influence a dependent variable or response. The mathematical models commonly used are represented by

$$
Y=\phi(s, f, d)+\varepsilon,
$$

where $Y$ is the machining response; $\phi$ is the response function; $s, f$, and $d$ are variables; and $\varepsilon$ is the error which is normally distributed about the observed response $Y$ with zero mean. The relationship between surface roughness and other independent variables can be represented as follows:

$$
R_{a}=C s^{x} f^{y} d^{z}
$$

where $C$ is a constant and $x, y$, and $z$ are exponents.

In order to determine constants and exponents, the mathematical model was linearized by performing a logarithmic transformation as follows:

$$
\ln R_{a}=\ln C+x \ln s+y \ln f+z \ln d .
$$


The constants and exponents $C, x, y$, and $z$ were determined by the method of least squares. The first order linear model, developed from the above functional relationship using least squares method, is as follows:

$$
Y_{1}=Y-\varepsilon=b_{0} x_{0}+b_{1} x_{1}+b_{2} x_{2}+b_{3} x_{3},
$$

where $Y_{1}$ is the estimated response based on the first-order equation; $Y$ is the measured surface roughness on a logarithmic scale; $x_{0}, x_{1}, x_{2}$, and $x_{3}$ are logarithmic transformations of cutting speed, feed rate, and depth of cut, respectively; $\varepsilon$ is the experimental error; and $b$ values are the estimates of corresponding parameters.

The general second order polynomial response is as follows:

$$
\begin{aligned}
Y_{2}=Y-\varepsilon= & b_{0} x_{0}+b_{1} x_{1}+b_{2} x_{2}+b_{3} x_{3}+b_{12} x_{1} x_{2} \\
& +b_{13} x_{1} x_{3}+b_{23} x_{2} x_{3}+b_{11} x_{1}{ }^{2}+b_{22} x_{2}{ }^{2} \\
& +b_{33} x_{3}{ }^{2}
\end{aligned}
$$

where $Y_{2}$ is the estimated response based on the second order equation. The parameters $b_{1}, b_{2}, b_{3}, b_{12}, b_{13}, b_{23}, b_{11}, b_{22}$, and $b_{33}$ are to be estimated.

The experiment was conducted on EN-31 material for its face mill and the results $R_{a}, T_{w}$, and $T_{v}$ were obtained by varying the variables speed $(s)$, axial feed $(f)$, and depth of cut $(d)$. The machinability performances obtained for the milling process were analyzed to evaluate the machinability and formulated in the RSM to develop the prediction model for the performance parameters for the required range of design variables [15].

In the analysis, procedure for the approximation of the response was achieved by developing by RSM model equation which represents a model of machining response.

The general form of a quadratic polynomial, which gives the relation between response surface $y$ and the process variable $x$ under investigation, is given by

$$
Y=b_{0}+\sum_{i=1}^{k}\left(b_{i} x_{i}\right)+\sum_{i=1}^{k}\left(b_{i i} x^{2}\right)+\sum_{i<j} b_{i j} x_{i},
$$

where $b_{0}$ is the constant, $b_{i}$ is the linear term coefficient, $b_{i i}$ is the quadratic term coefficient, and $b_{i j}$ is the interaction term coefficient. The equations of transformation provided variables for coded $x_{i}(i=1,2,3,4)$ as follows:

$$
\begin{aligned}
& X_{1}=\frac{\left(s-s_{0}\right)}{\Delta s}, \\
& X_{2}=\frac{\left(f-f_{0}\right)}{\Delta f}, \\
& X_{3}=\frac{\left(d-d_{0}\right)}{\Delta d},
\end{aligned}
$$

where $s, f, d$, and $r$ are the coded variables of machining parameters. The initial conditions of these parameter start from zero and $\Delta s, \Delta f$, and $\Delta d$, the parameter variation intervals. $T_{w}, R_{a}$, and $T_{v}$ referred to as $Y\left(T_{w}\right), Y\left(R_{a}\right)$, and $Y\left(T_{v}\right)$,
TABLE 3: Factors and selected levels in milling operations.

\begin{tabular}{lccc}
\hline Factor & \multicolumn{3}{c}{ Level } \\
& -1 & 0 & 1 \\
\hline$A$-cutting speed $(\mathrm{m} / \mathrm{min})$ & 100 & 140 & 180 \\
$B$ - axial feed (mm/tooth) & 0.1 & 0.15 & 0.2 \\
$C$-depth of cut $(\mathrm{mm})$ & 0.75 & 1.0 & 1.25 \\
\hline
\end{tabular}

TABLE 4: Summary of regression analysis.

\begin{tabular}{lccc}
\hline Responses & $S$ value & $R^{2} \%$ & Adj. $R^{2} \%$ \\
\hline Surface roughness $\left(R_{a}\right)$ & 0.61 & 60.97 & 40.31 \\
Tool life $\left(T_{L}\right)$ & 5.04 & 90.13 & 84.90 \\
Tool vibration $\left(T_{v}\right)$ & 3.36 & 48.95 & 42.29 \\
\hline
\end{tabular}

respectively, are the response functions. The variable needed to develop the response surface models is composed of the investigational design by the collections of observed values. During grouping, the factors are coded within the range of +1 and -1 levels that are produced at the eight key positions; here the midpoint is between the lower and higher ranges of each individual factor. Table 3 shows the level of machining parameters and their corresponding ranges for RSM design (Table 6).

The model fitness is to decide the proximity of the adjusted $R^{2}$ with $R^{2}$ value. Table 4 indicates the nearer value of adjusted $R^{2}$ and $R^{2}$ for all cases. The RSM model is required to develop the interaction among the available responses $Y\left(R_{a}\right), Y\left(T_{L}\right)$, and $Y\left(T_{v}\right)$ and the machining parameters $x(s, f$, and $d)$. Table 5 shows the standard three variable RSM models with 27 runs are simulated with experimental responses and the response equations are developed. From the RSM model the empirical model for 27 runs was achieved and carried out in the forms of experiment and the results were observed corresponding to the response design model (Table 5). Consider

$$
\begin{aligned}
Y\left(R_{a}\right)= & 0.13+0.049 X_{1}+0.30 X_{2}+0.38 X_{3}-0.051 X_{1} X_{2} \\
& +0.24 X_{1} X_{3}+0.45 X_{2} X_{3}+0.47 X_{1}^{2}-0.039 X_{2}^{2} \\
& +0.43 X_{3}^{2}, \\
Y\left(T_{L}\right)= & 4.31-1.30 X_{1}-0.82 X_{2}-0.51 X_{3}+0.44 X_{1} X_{2} \\
& -0.005039 X_{1} X_{3}-0.047 X_{2} X_{3}-0.32 X_{1}^{2} \\
& +0.13 X_{2}^{2}-0.22 X_{3}^{2}, \\
Y\left(T_{v}\right)= & 18.15+1.28 X_{1}+2.56 X_{2}+2.39 X_{3}+2.25 X_{1} X_{2} \\
& -0.83 X_{1} X_{3}+2.701 E-016 X_{2} X_{3}+1.06 X_{1}^{2} \\
& +0.89 X_{2}^{2}-0.94 X_{3}^{2} .
\end{aligned}
$$

Equations in (9) are the required equations of the RSM model for surface roughness $\left(R_{a}\right)$, tool Life $\left(T_{L}\right)$, and tool vibration 
TABLE 5: Regression analysis coefficient for tool life $\left(T_{L}\right)$, surface roughness $\left(R_{a}\right)$, and tool vibration $\left(T_{v}\right)$.

\begin{tabular}{|c|c|c|c|c|c|c|}
\hline & \multicolumn{2}{|c|}{ Surface roughness $\left(R_{a}\right)$} & \multicolumn{2}{|c|}{ Tool life $\left(T_{L}\right)$} & \multicolumn{2}{|c|}{ Tool vibration $\left(T_{v}\right)$} \\
\hline & Coefficient & $P$ value & Coefficient & $P$ value & Coefficient & $P$ value \\
\hline Intercept & 0.13 & 0.0262 & 4.31 & 0.0001 & 18.15 & 0.0107 \\
\hline$X_{1}(s)$ & 0.049 & 0.7350 & -1.30 & 0.0001 & 1.28 & 0.1089 \\
\hline$X_{2}(f)$ & 0.30 & 0.0511 & -0.82 & 0.0001 & 2.56 & 0.0035 \\
\hline$X_{3}(d)$ & 0.38 & 0.0165 & -0.51 & 0.0002 & 2.39 & 0.0057 \\
\hline$X_{1} X_{2}$ & -0.051 & 0.7762 & 0.44 & 0.0042 & 2.25 & 0.0263 \\
\hline$X_{1} X_{3}$ & 0.24 & 0.1920 & $-5.039 E-003$ & 0.9703 & -0.83 & 0.3802 \\
\hline$X_{2} X_{3}$ & 0.45 & 0.0214 & -0.047 & 0.7312 & $2.701 E-016$ & 1.0000 \\
\hline$X_{1}^{2}$ & 0.47 & 0.0759 & -0.32 & 0.1028 & 1.06 & 0.4309 \\
\hline$X_{2}{ }^{2}$ & -0.039 & 0.8760 & 0.13 & 0.4993 & 0.89 & 0.5060 \\
\hline$X_{3}{ }^{2}$ & 0.43 & 0.1006 & -0.22 & 0.2495 & -0.94 & 0.4801 \\
\hline
\end{tabular}

$\left(T_{v}\right)$ and $X_{1}, X_{2}$, and $X_{3}$ are the significant decoded values of speed, axial feed, and depth of cut correspondingly.

3.2. Analysis of Mathematical Model. In order to check the response surface methodology design, analysis of variance (ANOVA) was used. Table 7 shows the ANOVA of regression parameters of the predicted surface response model for surface roughness, tool life, and tool vibration. The model fitness for the response parameters, shown in Table 7, is 2.95, 26.38, and 3.63 for the surface roughness, tool life, and vibration amplitude, respectively. The percentage of $F$ distribution for the standard $95 \%$ confidence limit is 4.06 . The model is within the $95 \%$ of confidence limit. It is predicted that the value of $R_{a}, T_{L}$, and $T_{v}$ is within confidence limit and the models are found to be significant.

\section{Results and Discussion}

Mathematical models were developed to predict the surface roughness, acceleration vibration amplitude, and tool wear by relating them with process parameters such as cutting speed, axial feed rate, and depth of cut. Effects of these process parameters on surface roughness, tool vibration, and tool life have been discussed here.

4.1. Effect of Speed, Feed, and Depth of Cut on Surface Roughness. The response surface graph in Figures 4 and 5 shows the combined effect of feed and cutting speed on $R_{a}$ value by varying the depth of cut from minimum to maximum. $X_{1}$ represents $=A=$ cutting speed (CS), $X_{2}$ represents = $B=$ feed rate (FR), and $Y$ represents (surface roughness) $=$ $R_{a}$ value. It further indicates that as the cutting speed increases, surface roughness decreases but at low level of feed that is $0.10 \mathrm{~mm} /$ tooth the surface roughness increases. However, at higher value of feed rate $0.2 \mathrm{~mm} /$ tooth, $R_{a}$ value first decreases at the speed from 100 to $140 \mathrm{~m} / \mathrm{min}$; then $R_{a}$ increases as speed increases from 100 to $180 \mathrm{~m} / \mathrm{min}$ as shown in Figure 4. In Figure 5, the response surface shows the combined effect of cutting speed and depth of cut on surface roughness. Cutting speed is represented on $X-1$ axis and depth of cut is represented on $X-2$ axis and $R_{a}$ is represented

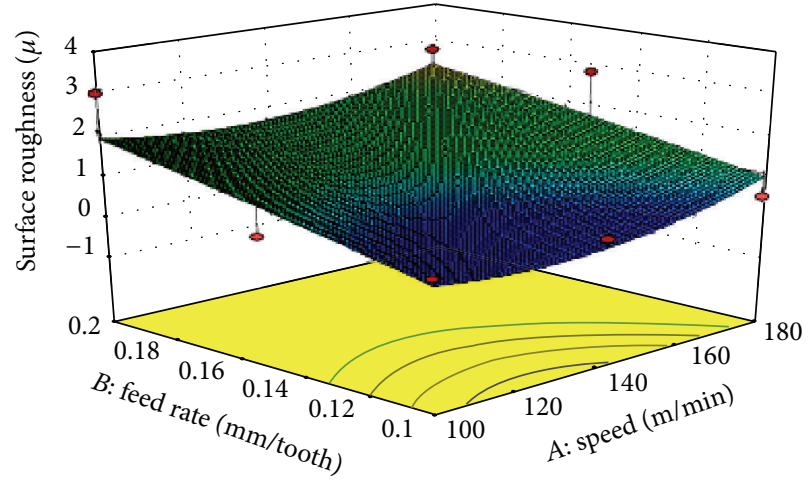

Figure 4: Effect of speed $(A)$ and feed $(B)$ on S.R.

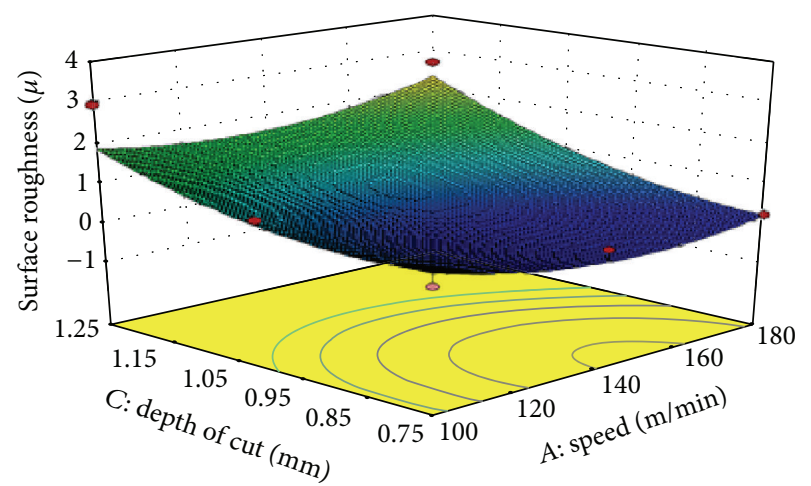

Figure 5: Effect of d.o.c $(C)$ and speed $(A)$ on S.R.

on $Y$-axis. The trend of response surface shows that $R_{a}$ value decreases on increasing the cutting speed from $100 \mathrm{~m} / \mathrm{min}$ to $140 \mathrm{~m} / \mathrm{min}$ and $R_{a}$ increases on further increase in cutting speed from 140 to $180 \mathrm{~m} / \mathrm{min}$.

The interaction plot in Figure 6 shows the effect of feed and depth of cut on $R_{a}$ value. It indicates that with increase of feed and depth of cut, $R_{a}$ value increases. At lowest value of depth of cut, that is, $0.75 \mathrm{~mm}, R_{a}$ value increases with increase in feed rate, that is, from 0.10 to $0.2 \mathrm{~mm} /$ tooth, whereas at highest value of depth of cut, that is, $1.25 \mathrm{~mm}, R_{a}$ value 


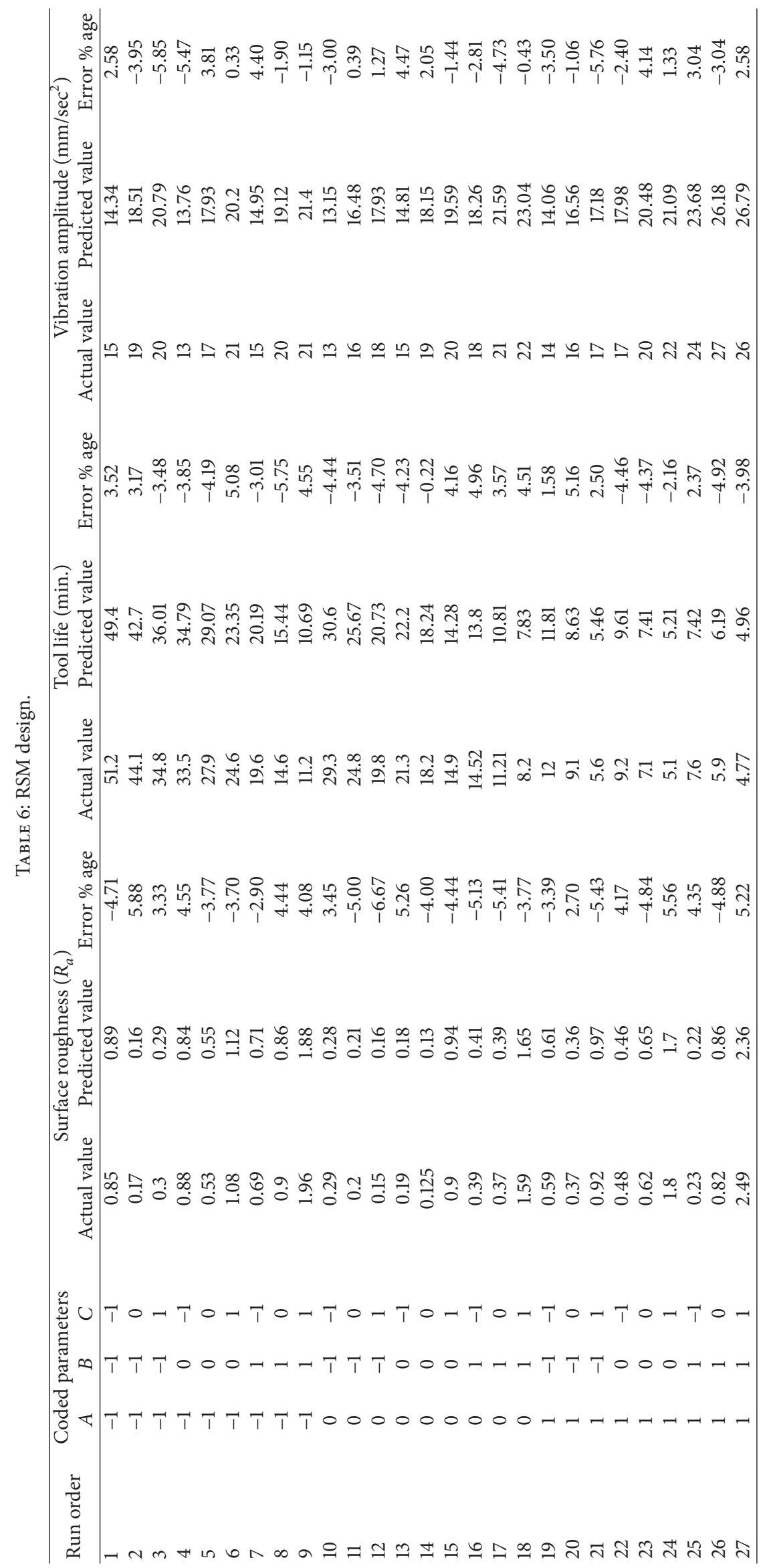




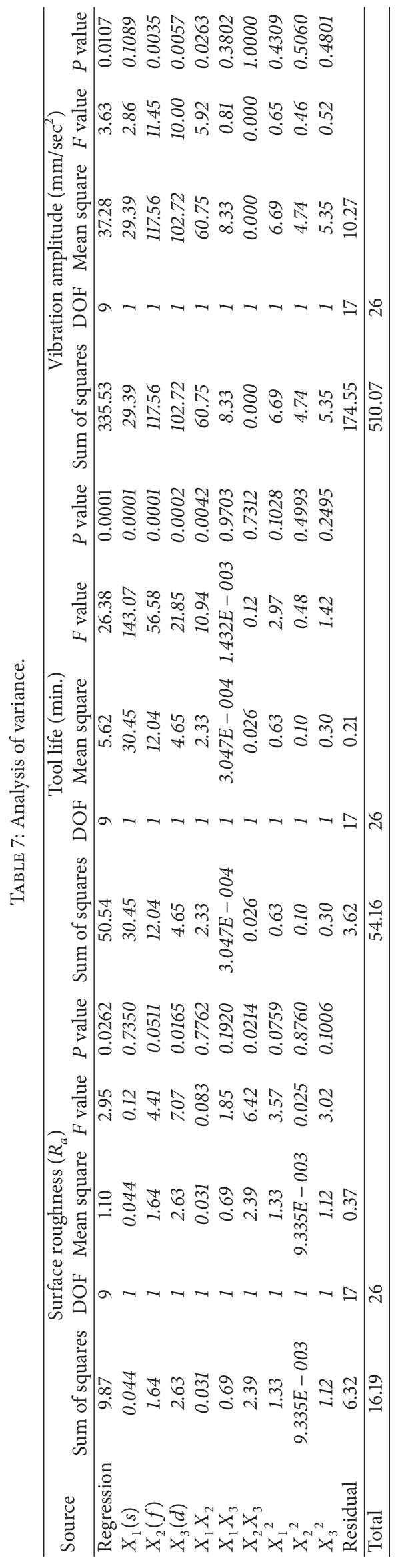




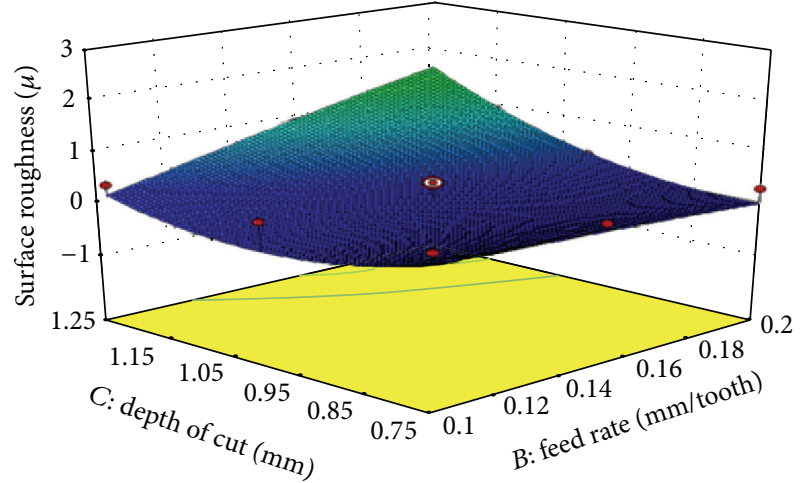

FIGURE 6: Effect of d.o.c $(C)$ and feed $(B)$ on SR.

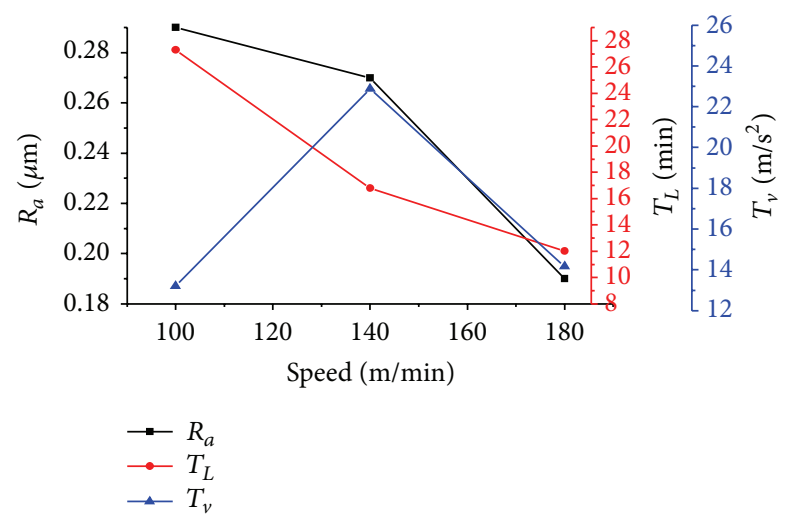

FIgURE 7: Direct effect of speed on SR, $T_{L}$, and $T_{v}$.

increases more with increase in feed rate, that is, from 0.10 to $0.2 \mathrm{~mm} /$ tooth. Figure 6 shows $R_{a}$ value as 4.81 at maximum cutting speed of $180 \mathrm{~m} / \mathrm{min}, 0.2 \mathrm{~mm} /$ tooth of feed and $1.25 \mathrm{~mm}$ of depth of cut.

In the milling process, the effects of cutting speed, feed rate, and depth of cut were experimentally investigated. It is clear from Figure 7 that the cutting speed $(s)$ has substantial effect on $R_{a}$, tool life, and tool vibrations. It shows that surface roughness $\left(R_{a}\right)$ decreases with the increase in the cutting speed. There is significant effect of cutting speed on tool life, as cutting speed increases tool life decreases. It is also found that tool vibration due to the cutting speed is unequally distributed. When the cutting speed is in the range of 100 to $140 \mathrm{~m} / \mathrm{min}$, the tool vibration increases, whereas it decreases for the cutting speeds ranging from 140 to $180 \mathrm{~m} / \mathrm{min}$. This process resulted in drastic reduction in the tool life and surface roughness, but this also led to decrease in the tool vibration. At low cutting speeds the built-up edge (BUE) is formed and the chip fracture readily produces the rough surface. When cutting speed increases, BUE vanishes and chip fracture decreases and hence surface roughness decreases.

4.2. Effect of Speed, Feed, and Depth of Cut on Tool Life. Figure 8 shows that the tool life improves with the decrease in cutting speed thereby confirming the classical theory. The interpretation of parameters with RSM actually shows the

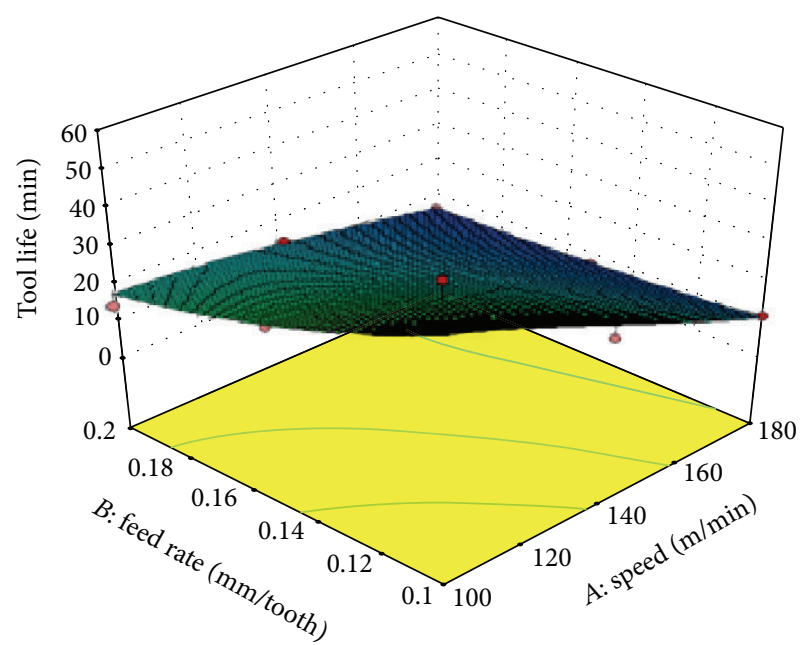

Figure 8: Effect of speed $(A)$ and feed $(B)$ on tool Life.

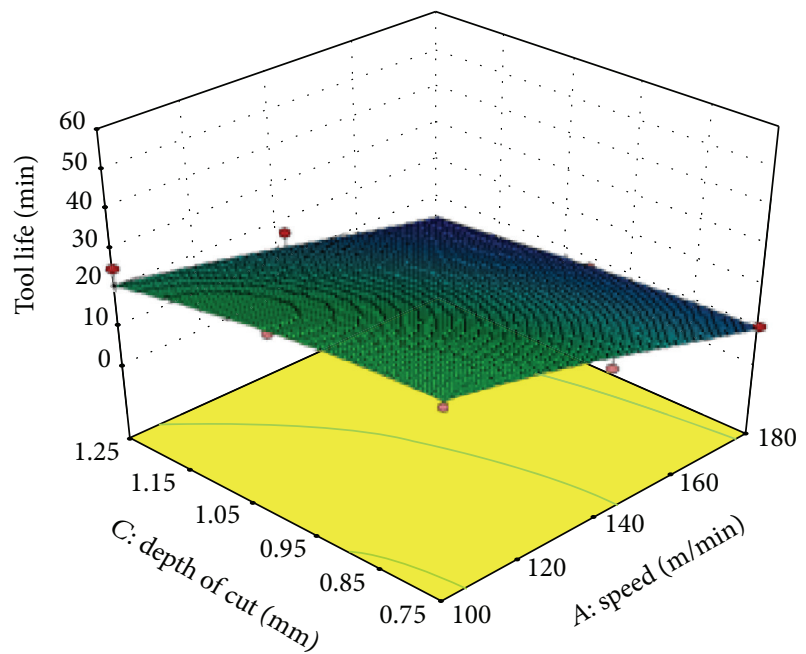

Figure 9: Effect of speed $(A)$ and d.o.c $(C)$ on tool life.

response with a surface. This method alone can used to analysis and visualize the changes that occur in responses by varying the input parameters.

Figure 8 shows that with the increase of cutting speed $(A)$ and feed $(B)$ from their lower to higher values, the tool life decreases, which verifies the significance of model of tool life and regression analysis of the equation. Figure 9 shows the combined effect of speed $(A)$ and depth of cut $(C)$ on tool life. It is clear from Figure 9 that with the increase of cutting speed, tool life decreases, but tool life decreases at low speed with increase in depth of cut.

The graph shown in Figure 10 further validates the model, as it shows the most significant effect of feed $(B)$ and depth of cut $(C)$ on tool life. It is clear from Figure 10 that with increase of feed, tool life decreases. Moreover, a steep inclination with the highest tool life value in the response surface can be seen in this graph. On analyzing this graph further, it can be observed that the maximum value of tool life reaches $48.723 \mathrm{~min}$. 


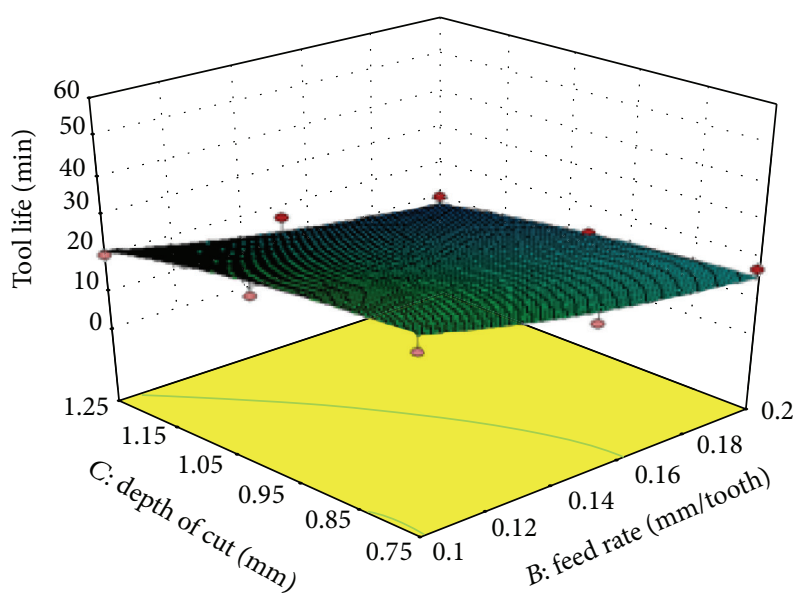

Figure 10: Effect of d.o.c $(C)$ and feed $(B)$ on tool Life.

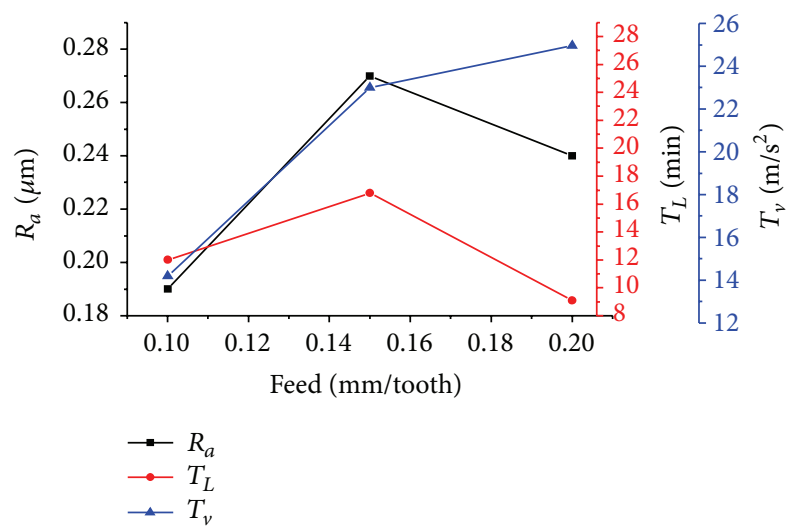

FIgURE 11: Direct effect of feed on SR, $T_{L}$, and $T_{v}$.

Figure 11 depicts the direct effect of feed on surface roughness, tool life, and tool vibrations. It is evident from Figure 11 that the surface roughness increases with increase in the feed rate and then slightly decreases. There is significant effect on tool life by the speed such that tool life increases with increase in feed and then subsequently decreases. It is also seen that the tool vibration also increases with the increase in feed rate. Hence for better tool life optimum feed rate is $0.15 \mathrm{~mm} /$ tooth and for surface roughness and tool vibration lower feed is recommend, that is, at the feed rate of $0.10 \mathrm{~mm} /$ tooth. As feed rate increases, the thickness of uncut chip also increases, thereby increasing the force and the work done during machining. Also, the heat was generated and load was found to increase per cutting edge and unit length, which led to increase in tool wear. At lower feed rate the work piece was accompanied by feed marks and producing more surface roughness. So in comparing the minimum and maximum ranges of the feed rates, the $0.15 \mathrm{~mm} /$ tooth was found to be optimum.

4.3. Effect of Speed, Feed, and Depth of Cut on Tool Vibration. The response surface graph shows the increase in vibration amplitude value by combined effect of cutting speed and feed

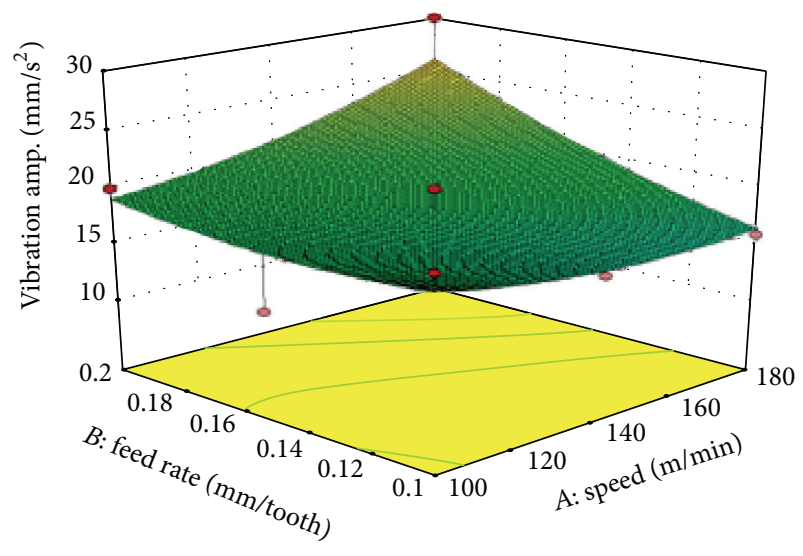

Figure 12: Effect of speed $(A)$ and feed $(B)$ on tool vibration.

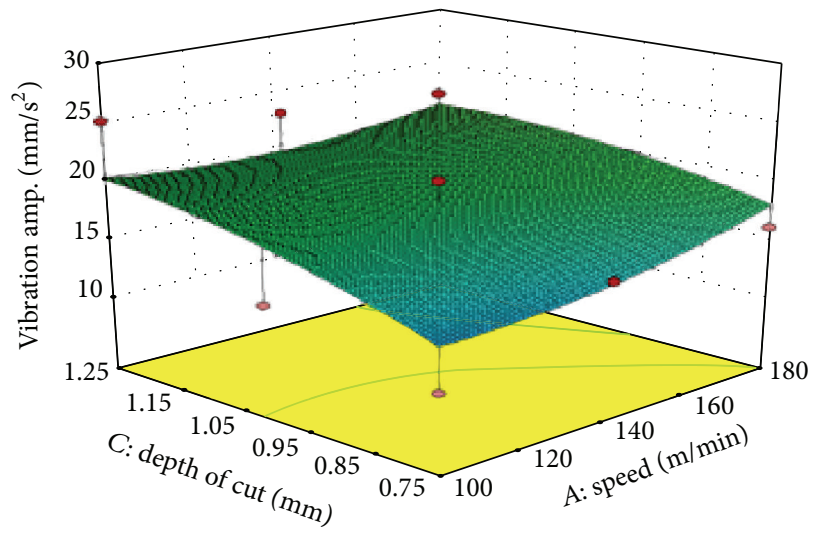

Figure 13: Effect of speed $(A)$ and d.o.c $(C)$ on tool vibration.

shown in Figures 12 to 14 which verifies the significance of model and proves it to be theoretically correct. The response surface graph in Figures 12 and 13 shows the combined effect of feed and cutting speed on vibration amplitude value by varying the depth of cut from minimum to maximum. $X$ 1 represents cutting speed $=A, X-2$ represents feed rate $=$ $B$, and $Y$ represents vibration amplitude value. Figure 12 indicates that as the cutting speed and feed increase, tool vibration also increases. However low tool vibration is found at low speed and low feed. As shown in Figure 13 tool vibration also increases with increase in depth of cut. The same affect can be seen by increasing the depth of cut and feed rate as in Figure 14. Figure 15 shows the direct effect of feed on other output parameters. At lower depth of cut, that is, d.o.c at 0.75 , we find lower tool life and tool vibration with better surface finish. With the increase of d.o.c, that is, at $1.0 \mathrm{~mm}$, surface roughness and tool vibration increase, but tool life decreases. Further with increase in depth of cut to $1.25 \mathrm{~mm}$ tool life and surface roughness increase while tool vibration remains almost constant.

As the tool approaches approached the workpiece, the vibrations caused in the workpiece were found to be more. As the asymptotic border line of stability reached a vital depth of cut, the vibratory forces in the workpiece were reduced a lot. 


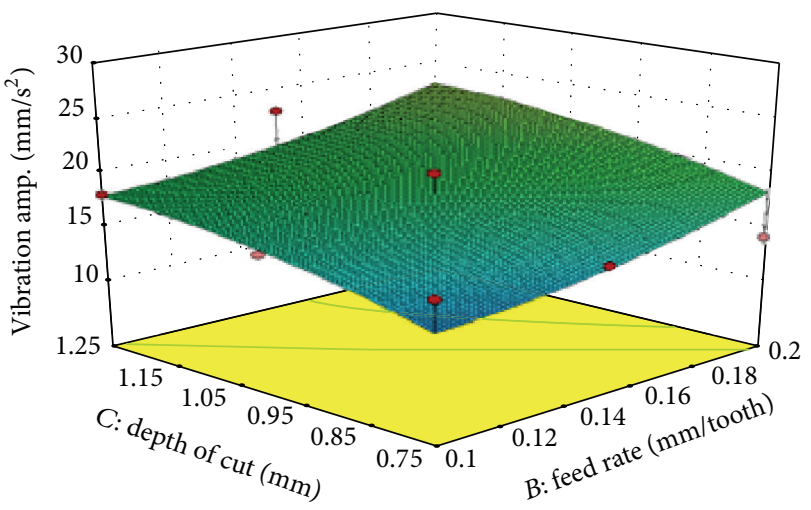

Figure 14: Effect of d.o.c (C) and feed $(B)$ on tool life.

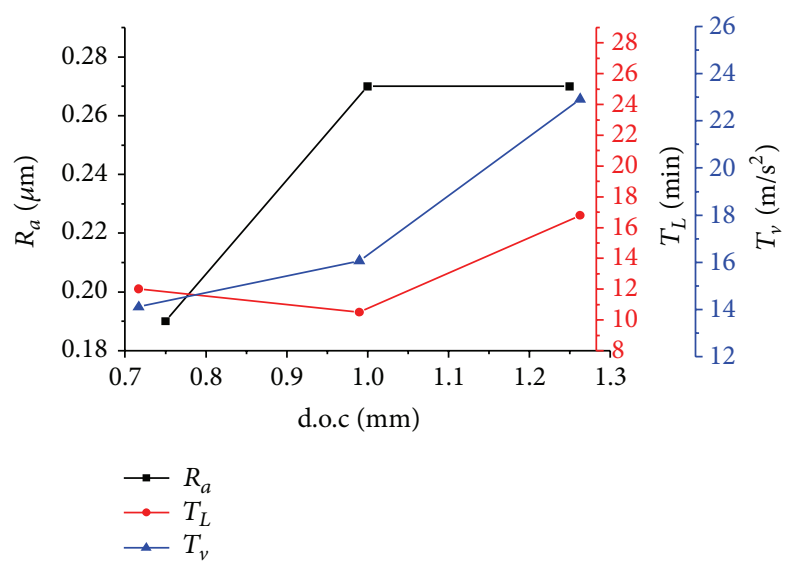

FIgURE 15: Direct effect of depth of cut on SR, $T_{L}$, and $T_{v}$.

To reduce the tool wear rate and to keep better surface finish, the depth of cut is to be maintained at the optimum (i.e., at $1.25 \mathrm{~mm}$ ) though the increase in feed rate provided the low cutting forces according to Ding et al. [16].

Vibrations in milling are induced due to the interrupted cutting operations. The exciting forces are generated by the teeth as it enters and leaves the workpiece. The variation in chip thickness leads to self-exciting vibrations. Effect of cutting parameters, $A$ : speed, $B$ : feed, and $C$ : depth of cut, on tool vibration can be understood by perturbation graph shown in Figure 16. Graph indicates the slope of each factor for tool vibration. Factor having more slope depicts that factor has more influence on the process. As clear from Figure 16 speed has almost straight line which indicates that it has less significant factor than others, while feed rate and depth of cut have more influence on tool vibration than cutting speed.

4.4. Exploring Solutions via Ramps View. Figure 17 shows the ramp display of machining parameters for interpretation of optimum solution parameters. The optimum results are obtained to achieve the objective of the study, that is, to minimize the surface roughness and tool vibration during machining. A dot on each ramp reflects the factor setting or response prediction for that solution. The height of the dot shows the desirability of the process. The red ones represent

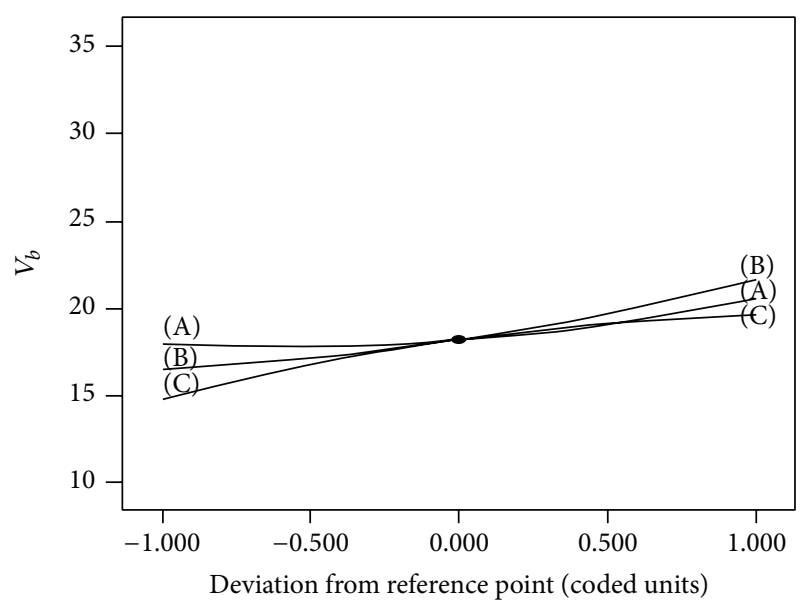

Actual factors

(A) speed $=140.00$

(B) feed $=0.15$

(C) depth of cut $=1.00$

FIGURE 16: Perturbation graph showing effect of cutting parameter on tool vibration.

that the component levels move around quite a bit, but the responses remain within their goals, that is, desirability of 1 .

4.5. Validation of Model. Mathematical model of a process has an advantage that we can experiment with the model rather than the process. Invariably the process can be simulated by using the mathematical model with simulation software. The results can often be used to indicate what additional data would be beneficial for refining an existing model to make it more realistic and more useful.

The validity of the model is checked for the levels of the parameter, which has not been included in the experimental design. The validations of the experimental data are shown in Table 8. It is clearly understood that the error between the actual value and predicted value is $4.89 \%$ which also confirms the validity of the model.

\section{Conclusions}

In the present study, the machining parameters in $\mathrm{CNC}$ milling of EN-31 die steel machining with tungsten carbide tool bit have been optimized using response surface methodology. Full factorial (3K) orthogonal array has been used and twenty-seven experiments are carried out. The primary object is to develop mathematical models based on experimental results, for obtaining low surface roughness and cutting tool vibration. The predicted surface roughness from the model is compared to the values measured experimentally. The optimum cutting parameters for minimum surface roughness and tool vibration based on the analysis of experiment results are cutting speed $=143.6 \mathrm{~m} / \mathrm{min}$, feed $=0.1 \mathrm{~mm} /$ tooth, and depth of cut $=1.25 \mathrm{~mm}$ which resulted in surface roughness of 0.189 and tool vibration of 17.772 . The validity of the model 


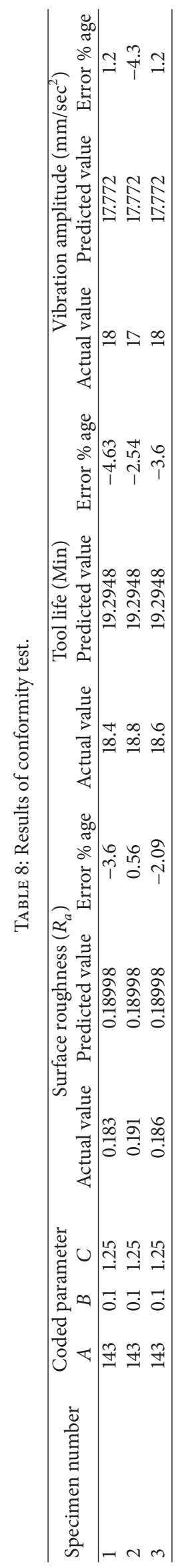




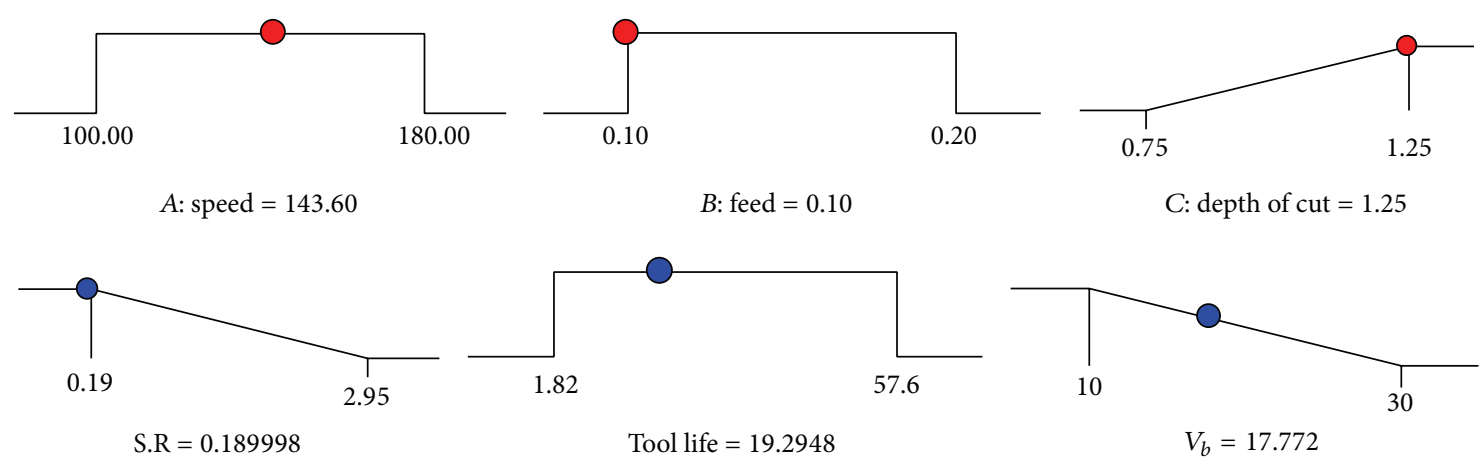

Desirability $=0.849$

FIGURE 17: Ramp graph showing optimal solution.

has been checked by conducting conformity test with maximum error of $4.3 \%$.

\section{Conflict of Interests}

The authors declare that there is no conflict of interests regarding the publication of this paper.

\section{References}

[1] W. A. Kline, R. E. Devor, and I. A. Shareef, "The prediction of surface accuracy in end milling," Journal of Engineering for Industry, vol. 104, no. 3, pp. 272-278, 1982.

[2] A. Hamdan, A. A. D. Sarhan, and M. Hamdi, "An optimization method of the machining parameters in high-speed machining of stainless steel using coated carbide tool for best surface finish," International Journal of Advanced Manufacturing Technology, vol. 58, no. 1-4, pp. 81-91, 2012.

[3] P. V. S. Suresh, P. V. Rao, and S. G. Deshmukh, "A genetic algorithmic approach for optimization of surface roughness prediction model," International Journal of Machine Tools and Manufacture, vol. 42, no. 6, pp. 675-680, 2002.

[4] J. P. Kumar and K. Thirumurugan, "Optimization of machining parameters for milling titanium using Taguchi method," International Journal of Advanced Engineering Technology, vol. 3, no. 2, pp. 108-113, 2012.

[5] J. Z. Zhang and J. C. Chen, "Tool condition monitoring in an end-milling operation based on the vibration signal collected through a microcontroller-based data acquisition system," The International Journal of Advanced Manufacturing Technology, vol. 39, no. 1-2, pp. 118-128, 2008.

[6] B. C. Routara, A. Bandyopadhyay, and P. Sahoo, "Roughness modeling and optimization in CNC end milling using response surface method: effect of workpiece material variation," International Journal of Advanced Manufacturing Technology, vol. 40, no. 11-12, pp. 1166-1180, 2009.

[7] X. Cui and J. Zhao, "Cutting performance of coated carbide tools in high-speed face milling of AISI H13 hardened steel," The International Journal of Advanced Manufacturing Technology, vol. 71, no. 9-12, pp. 1811-1824, 2014.

[8] K. V. M. K. Raju, G. R. Janardhana, P. N. Kumar, and V. D. P. Rao, "Optimization of cutting conditions for surface roughness in
CNC end milling," International Journal of Precision Engineering and Manufacturing, vol. 12, no. 3, pp. 383-391, 2011.

[9] N. V. Prajina, "Multi response optimization of CNC end milling using response surface methodology and desirability function," International Journal of Engineering Research and Technology, vol. 6, no. 6, pp. 739-746, 2013.

[10] M.-Y. Wang and H.-Y. Chang, "Experimental study of surface roughness in slot end milling AL2014-T6," International Journal of Machine Tools and Manufacture, vol. 44, no. 1, pp. 51-57, 2004.

[11] H. Öktem, T. Erzurumlu, and H. Kurtaran, "Application of response surface methodology in the optimization of cutting conditions for surface roughness," Journal of Materials Processing Technology, vol. 170, no. 1-2, pp. 11-16, 2005.

[12] I. A. Rahim, M. A. Miskam, O. Sidek, S. A. Zaharudin, and S. K. K. Mohd, "Development of a vibration measuring unit using a microelectromechanical system accelerometer for machine condition monitoring," European Journal of Scientific Research, vol. 35, no. 1, pp. 150-158, 2009.

[13] W. Chen, "Cutting forces and surface finish when machining medium hardness steel using CBN tools," International Journal of Machine Tools and Manufacture, vol. 40, no. 3, pp. 455-466, 2000.

[14] Korloy, Korly Cutting Tool 2012, Korloy India Tooling, 2012.

[15] D. C. Montgomery, Design and Analysis of Experiments, Wiley, New York, NY, USA, 5th edition, 1998.

[16] T. Ding, S. Zhang, Y. Wang, and X. Zhu, "Empirical models and optimal cutting parameters for cutting forces and surface roughness in hard milling of AISI H13 steel," The International Journal of Advanced Manufacturing Technology, vol. 51, no. 1-4, pp. 45-55, 2010. 


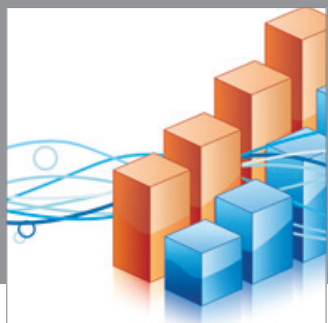

Advances in

Operations Research

mansans

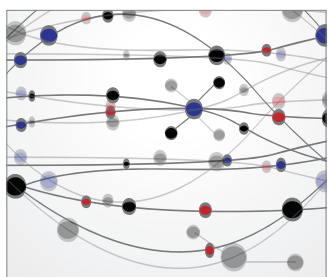

The Scientific World Journal
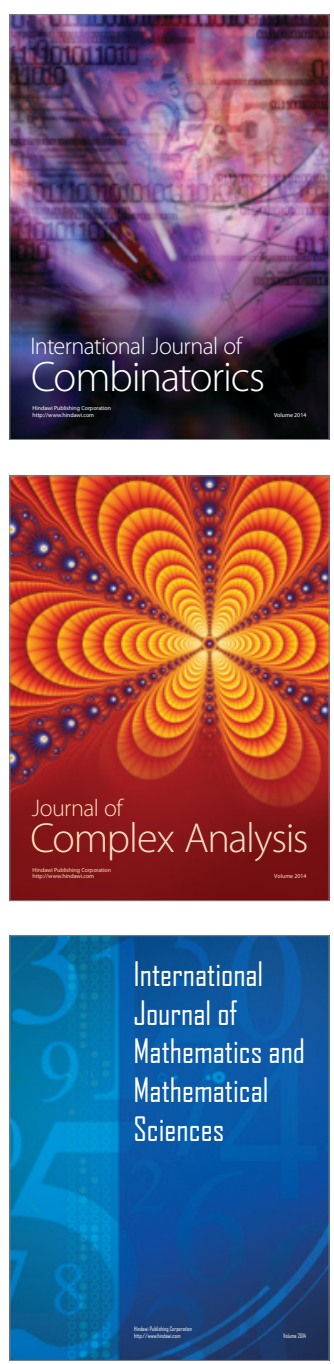
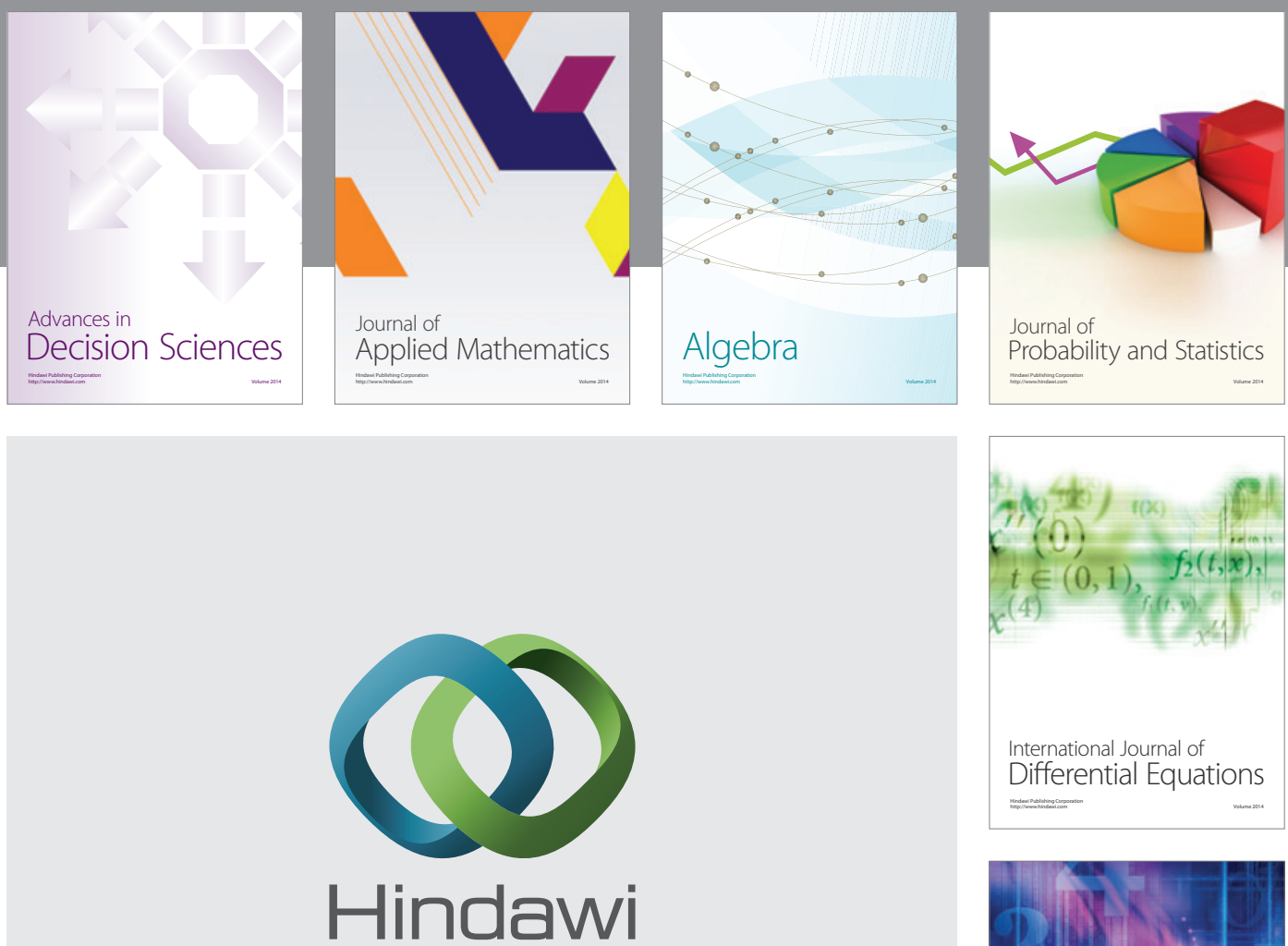

Submit your manuscripts at http://www.hindawi.com
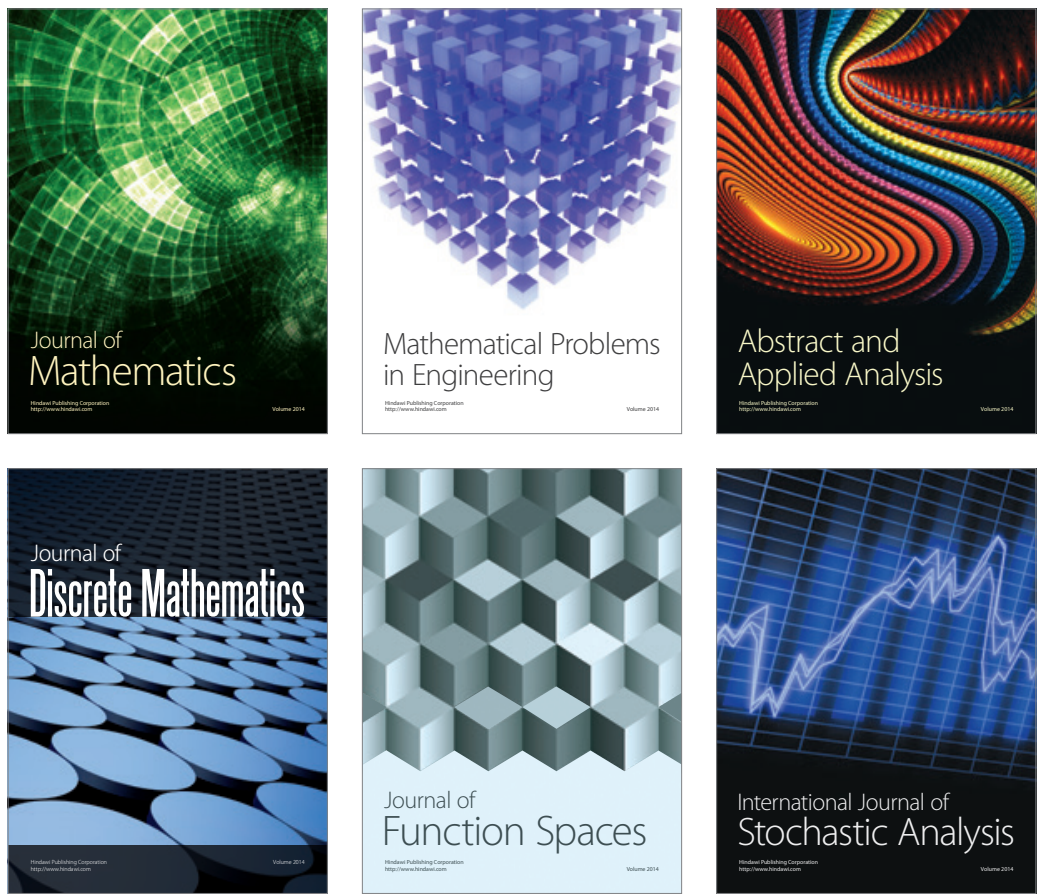

Journal of

Function Spaces

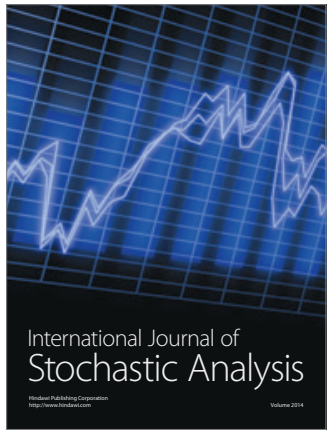

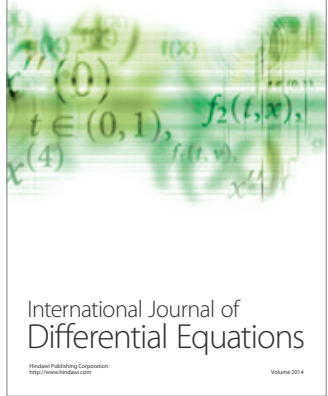
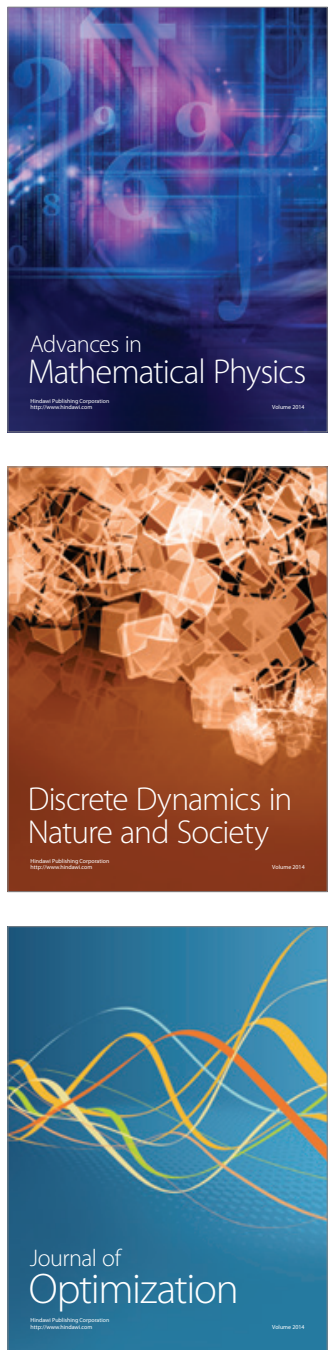